\title{
Pesquisas sobre a construção do conhecimento social no contexto brasileiro: estado da arte 2005- 2017
}

\author{
Eliane Giachetto Saravali ${ }^{1}$ \\ Taislene Guimarães ${ }^{2}$ \\ Rafaela Carolina da Silva ${ }^{3}$
}

\begin{abstract}
RESUMO
O texto oferece uma ampla revisão das pesquisas realizadas no contexto brasileiro, referentes à construção do conhecimento social na perspectiva piagetiana. As bases de dados consultadas foram Scielo, Portal de Periódicos e Banco de Teses da CAPES e Bibliotecas Digitais das instituições referenciadas neste último, mediante a utilização dos seguintes termos, em busca avançada: conhecimento social, Jean Piaget, epistemologia genética, crenças, noções sociais, Juan Delval e interação social. Foram encontradas 74 referências, entre 2005 e 2017, analisadas sob os seguintes aspectos: veículo de publicação, autores mais produtivos, autores mais citados, instituições de origem das pesquisas, faixa etária dos participantes, delineamentos metodológicos utilizados e as temáticas abordadas nos estudos. Conclui-se, entre outros, a respeito da relevância desses trabalhos e da atualidade da obra piagetiana, referencial teórico que sustenta esse tipo de compreensão sobre a apropriação do mundo social.
\end{abstract}

PALAVRAS-CHAVE: Conhecimento Social. Epistemologia Genética. Estado da Arte.

Construction of social knowledge e researchs in the Brazilian context: state of art 2005-2017

\footnotetext{
${ }^{1}$ Doutora em Educação. Docente do Departamento de Psicologia da Educação e do Programa de Pós-Graduação em Educação da Universidade Estadual Paulista - UNESP, campus de Marília, SP, Brasil. E-mail: eliane.saravali@marilia.unesp.br

${ }^{2}$ Doutora em Educação. Universidade Estadual Paulista - UNESP, campus de Marília, SP, Brasil. E-mail: taislene_ped@yahoo.com.br

${ }^{3}$ Doutoranda em Ciência da Informação. Universidade Estadual Paulista - UNESP, campus de Marília, SP, Brasil. Email: rafaelacarolinasilva@gmail.com
} 


\begin{abstract}
The paper offers a broad review of the research carried out in the Brazilian context, concerning the construction of social knowledge in a Piagetian perspective. The databases consulted were Scielo, Portal de Periódicos eBanco de Teses CAPES and the digital libraries of the institutions referenced, using the following terms, in advanced search: social knowledge, Jean Piaget, genetic epistemology, creed, social notions, Juan Delval, and social interaction. There were 74 references between 2005 and 2017, analyzed by the follow steps: vehicle of publication, more productive authors, more cited authors, origin of theresearch institutions, age range of the participants, methodological delineations,as well as the topics addressed in the studies. It concludes, among others, on the relevance of the works and the actuality of the Piagetian work, theoretical reference which supports this type of understanding about the appropriation of the social world.
\end{abstract}

KEYWORDS: Social Knowledge. Genetic Epistemology. State of Art.

$$
* * *
$$

\title{
Introdução
}

No presente texto, objetivamos sistematizar aspectos de um conjunto de pesquisas desenvolvidas no contexto brasileiro a respeito da construção do conhecimento social, sob a perspectiva piagetiana. Elegemos os últimos 12 anos (2005-2017) como período de análise, tendo em vista que as pesquisas referentes a esta temática começaram a ser publicadas no Brasil a partir de 1996 (GODOY, 1996; TORTELLA, 1996) e, não sendo possível uma análise detalhada de todo período nos limites de um artigo, optamos, neste momento, por dedicarmo-nos a sua segunda metade.

Primeiramente, julgamos oportuno apresentar uma questão essencial: delimitar o que significa "construção do conhecimento social na perspectiva piagetiana”. Na obra do mestre suíço, (Jean Piaget 1896-1980), podemos observar que o social pode se referir a dois aspectos diferentes de nossas vidas, tratados separadamente aqui apenas para fins didáticos, uma vez que 
para compreender o desenvolvimento é necessário ter em mente a construção e evolução de um sujeito epistêmico e de um sujeito psicológico, constantemente. Tais aspectos referem-se à interação social, fator do desenvolvimento, e ao social como objeto de conhecimento, caracterizado diferentemente dos objetos físicos ou matemáticos.

Assim, a interação, necessária à construção do conhecimento, jamais se referiu somente aos limites de um indivíduo e de um objeto físico, inanimado. É na e da interação social que vemos os indivíduos se libertarem de um pensamento egocêntrico, centrado na própria perspectiva; sem ela, dificilmente poderíamos falar em convivência e desenvolvimento moral, por exemplo.

Tal interação, que envolve a coordenação de diferentes perspectivas, possui também o componente da transmissão, daquilo que é proveniente dos antepassados, que se transfere por diferentes meios - o ensino, a televisão, os jornais etc. O conhecimento construído a partir dessa informação é, a nosso ver, parte importante do amplo processo de socialização, porém, insuficiente para a elaboração de ideias menos aparentes e estereotipadas sobre o mundo social.

Assim sendo, numa perspectiva piagetiana, precisamos compreender que essas construções socialmente compartilhadas não devem desconsiderar o papel de quem conhece. Isto é, a transmissão não exclui a assimilação que o sujeito faz, o sentido que ele é capaz de atribuir a esse novo objeto de conhecimento: "toda assimilação é uma reestruturação ou uma reinvenção" (PIAGET, 1998, p.48).

O conhecimento social refere-se ao conhecimento da sociedade e seu funcionamento, ao sistema de valores e crenças, bem como à compreensão dos diferentes papéis sociais das pessoas e nossas interações com elas (ENESCO, DELVAL, LINAZA, 1989). Trata-se do:

[...] conjunto de propriedades que os indivíduos atribuem a uma parcela da realidade, o que inclui as propriedades dos elementos, 
as relações entre eles, as explicações do porquê acontecem, as relações causais e muitas outras coisas. (DELVAL, 2013a, p. 16, tradução nossa).

Pensar, portanto, no conhecimento social, significa considerar, pormenorizadamente, como o sujeito se apropria daquilo que é socialmente construído e compartilhado em seu meio cultural, familiar, escolar. Debruçar-se sobre esses assuntos é ação investigativa mais recente, datada, no contexto internacional, da década de 70 do século passado e, no Brasil, da década de 90, como pontuado anteriormente.

Nos estudos de Delval (Delval, 2013b; Delval, Vila, 2008; Delval, Del Barrio, 1992; Delval, 1989; Denegri, Delval, 2002 a e b), podemos conhecer os processos percorridos para a construção desse tipo de conhecimento, assim como observar as noções elaboradas a respeito de diferentes conteúdos sociais. Tais estudos não devem ser analisados sob uma ótica anedótica ou apenas pela beleza em se dar voz a crianças e adolescentes. A importância desses estudos reside em poder acompanhar como um indivíduo se apropria do mundo social, de tal sorte que a qualidade e os limites dessa apropriação influenciarão as suas ações e sua relação com o mundo.

Estamos convencidos, portanto, que estudar a gênese dos conceitos sociais tem uma grande utilidade para entender as ideias adultas sobre a sociedade, e que é um requisito indispensável para desenvolver uma epistemologia genética das ciências sociais. (DELVAL, 2007, p. 50, tradução nossa).

Considerando o exposto, o presente artigo pretende contribuir àqueles que se dedicam ou pretendem se debruçar sobre a construção do conhecimento social, por meio da apresentação de pesquisas desenvolvidas no contexto nacional e da sistematização desta produção ainda pouco divulgada e que, certamente, nos traz não apenas significativas contribuições para os contextos psicológicos e pedagógicos do 
desenvolvimento infantil, mas também para a compreensão do pensamento adulto de nossa sociedade.

Nessa perspectiva, buscamos identificar, descrever e analisar os autores que formam a elite da produtividade deste campo no que se refere à produção e conteúdo e índices de citação. Para tanto, utilizamos a Lei do Elitismo de Price, advinda da bibliometria, que permite, por meio da análise da literatura produzida sobre um assunto, a identificação e a descrição dessa elite (ALVARADO, 2009).

Buscamos, como apontam Lakatos e Marconi (2003), percorrer os seguintes passos: a apreciação crítica do material; a decomposição dos elementos essenciais; a classificação do que foi encontrado e a análise final. Portanto, a análise permitiu destacar os pesquisadores que, no momento da realização desta pesquisa, mais produziram e foram mais citados na área de estudo (PRICE, 1963). Assim, procuramos os trabalhos que foram desenvolvidos numa perspectiva piagetiana e os que tratam de conteúdos sociais sob esse enfoque. Dessa forma, objetivamos concentrar os estudos que abordam os conteúdos sobre o funcionamento da sociedade em distintos aspectos e aqueles referentes às relações institucionalizadas, com seus respectivos papéis sociais (DELVAL, 2007). Ainda, para o autor, dentro deste recorte, há campos mais explorados, entre ele estão: o funcionamento econômico, a ordem política, as leis, a família, os papéis sexuais, as classes sociais, as profissões; essas são algumas temáticas recorrentes,também, em nosso contexto, conforme poderemos ver a seguir.

\section{Metodologia}

As pesquisas sobre a construção do conhecimento social, no Brasil, tiveram seu início em 1996 (GODOY, 1996; TORTELLA, 1996). Como a quantidade de pesquisas realizadas desde então é bastante grande para os limites de um artigo, optamos por apresentar os dados referentes ao período de 2005-2017, localizados entre março e agosto de 2017. 
As bases de dados consultadas foram: Scielo, Portal de Periódicos e Banco de Teses da CAPES, Bibliotecas Digitais das instituições referenciadas no Banco de Teses da CAPES e das instituições que possuem grupos consolidados dentro da temática, conforme indicado por Saravali, Mano, Guimarães (2015). Ainda, foram consultados os Anais de alguns dos principais eventos da área de Educação, a saber: Encontro Nacional de Didática e Práticas de Ensino (ENDIPE); Reuniões Anuais da Associação Nacional de Pós-Graduação e Pesquisa em Educação (ANPED); Encontros Nacionais de Professores do Programa de Educação Infantil e Ensino Fundamental (PROEPRE) e da área de Psicologia, como o Colóquio Internacional de Epistemologia e Psicologia Genéticas, entre outros.

Os termos utilizados para as buscas foram: conhecimento social, Jean Piaget, epistemologia genética, crenças, noções sociais, Juan Delval, interação social; sempre utilizando a ferramenta de busca avançada. Outra forma de busca se deu pela análise das referências bibliográficas de cada material encontrado, objetivando localizar quem era citado e/ou se havia outros estudos que não tínhamos encontrado nas referidas bases de dados.

A análise contemplou os resumos, o campo teórico, os objetivos, a metodologia, enfatizando-se a leitura dos resultados e as referências bibliográficas.

Apresentaremos, portanto, o resultado destas buscas com foco em seis principais aspectos: veículo de publicação, autores mais produtivos, autores mais citados, instituições de origem das pesquisas, faixa etária dos participantes, delineamentos metodológicos utilizados e as temáticas abordadas nos estudos. Acreditamos que a observação destes aspectos será fundamental para a compreensão e alcance do nosso objetivo.

\section{Resultados}

Dentre o material pesquisado, foram encontradas 74 referências ou produções. A distribuição do material encontrado, conforme o tipo de 
material (artigo, tese etc.) escolhido para divulgação da pesquisa pode ser observada na Tabela 1 , a seguir:

Tabela 1: Tipos de materiais das produções encontradas

\begin{tabular}{c|c}
\hline ANAIS & 28 \\
ARTIGOS & 20 \\
DISSERTAÇÕES & 17 \\
TCCs & 5 \\
TESES & 3 \\
CAPÍTULOS & 1 \\
\hline
\end{tabular}

Fonte: Elaborada pelas autoras.

Observamos que os artigos científicos não predominam dentre os veículos mais escolhidos para a divulgação das pesquisas realizadas, superados pelos Anais de evento. Essa é uma característica marcante na área de Educação que costuma, também, ter sua produção mais distribuída em livros e capítulos de livros, embora isso não tenha sido observado no nosso levantamento. Ao somarmos os materiais que estavam no formato teses, dissertações e Tccs temos 33\% de pesquisas que não foram divulgadas, ou seja, permaneceram em seus formatos originais. Isso pode explicar a razão pela qual, muitas vezes, vemos temáticas parecidas em pesquisas diferentes que não estabelecem um diálogo entre seus dados. Tal acontecimento enfatiza a importância do estado da arte como início de qualquer processo de pesquisa, permitindo, ao pesquisador, partir daquilo que já se conhece ou se produziu na área. Soma-se a isso o fato de que não há um rigor na utilização das palavras-chave, o que certamente pode dificultar o acesso à pesquisa realizada.

Para a análise da produtividade dos autores, utilizamos a Lei do Elitismo de Price, destacando-se 16 autores mais produtivos dentre o total de autores levantados, assim como 16 autores mais citados entre os autores mais produtivos.

O princípio de Price (1963, p. 46) é de que

Ao se contar a produção total daqueles que produzem $\mathrm{n}$ artigos, 
parece que o grande número de pequenos produtores contribuem tanto quanto o total do pequeno número dos grandes produtores; num simples caso esquemático, se pode mostrar uma simetria no ponto correspondente à raiz quadrada do número total de pessoas, ou as contribuições dos grandes produtores. [...] De fato, neste caso ideal, um quarto dos artigos terão sido escritos pelas duas pessoas mais produtivas, e outro quarto por aqueles que publicaram somente um ou dois itens (PRICE, 1963, p. 46).

Nesse contexto, da tabela geral de produtividade, separou-se os autores que mais publicaram no período, seja como autor principal ou como coautor. Excluiu-se os que publicaram apenas uma vez, considerando-se que, para a construção de um sociograma de Price, consistente e não carregado de muitas informações, são relevantes aqueles autores que tiveram mais de uma publicação. Isso decorre do objetivo da pesquisa, que buscou destacar o maior número de publicações e citações da área. Dessa maneira, foram considerados aqueles que tiveram, no mínimo, 2 publicações no período, restando16 autores, como mostra a Tabela 2, a seguir.

Tabela 2: Autores mais produtivos

\begin{tabular}{c|c}
\hline AUTOR & QUANTIDADE DE PUBLICAÇÕES \\
\hline SARAVALI, E. G. & 41 \\
GUIMARÃES, T. & 17 \\
MANO, A. de M. P. & 9 \\
MONTEIRO, T. A. & 9 \\
GUIMARÃES, K. P. & 5 \\
MELCHIORI, A. P. & 5 \\
OTHMAN, Z. A. S. & 5 \\
SILVA, C. F. da & 5 \\
STOLTZ, T. & 5 \\
ALMEIDA, E. Á. F. de & 4 \\
PIECZARKA, T. & 3 \\
COOPER, I. S. & 2 \\
COSTA, R. R. S. & 2 \\
PIRES, L. B. & 2 \\
ROCHA, M. & 2 \\
SOUZA, E. F. P. de & 2 \\
\hline
\end{tabular}

Fonte: Elaborada pelas autoras. 
Separou-se, então, os autores que foram mais citados, conforme apresentado na Tabela 3:

Tabela 3: Autores mais citados.

\begin{tabular}{c|c}
\hline AUTOR & QUANTIDADE DE CITAÇÕES \\
\hline PIAJET, J. & 284 \\
DELVAL, J. & 257 \\
DENEGRI, M. & 95 \\
ENESCO, I. & 81 \\
STOLTZ, T. & 79 \\
SARAVALI, E. G. & 72 \\
OTHMAN, Z. A. S. & 43 \\
AMAR, J. & 42 \\
GUIMARÃES, T. & 41 \\
CANTELL, V. C. B. & 40 \\
INHELDER, B. & 33 \\
NAVARRO, A. & 33 \\
PIECZARKA, T. & 30 \\
TORTELLA, J. C. B. & 30 \\
ARAÚJO, R. M. B. de & 24 \\
BAPTISTELLA, E. C. F. & 22 \\
\hline
\end{tabular}

Fonte: Elaborada pelas autoras.

O critério de escolha dos autores foi que eles tivessem pelo menos 2 citações ou mais de uma publicação, levando em conta que, para a Lei do Elitismo de Price, o total de apenas uma produtividade por autor é desconsiderável. Na tabela 3 , os 4 primeiros autores não são brasileiros, assim como AMAR,J.; INHELDER, B. e NAVARRO, A.

A partir desses dados, foi possível construir um sociograma para melhor ilustrar as relações existentes entre os autores mais produtivos e os autores mais citados por eles. Sendo assim, na Figura 1, os círculos vermelhos são os autores mais produtivos e os quadrados azuis são os mais citados. A linha que sai do ponto vermelho e chega até o azul mostra que o autor vermelho citou o azul. As linhas mais grossas mostram os autores que tiveram maior número de citações. Os autores duplicados, vermelhos e azuis, são produtivos e também citados. 
Figura 1: Relações entre os autores mais produtivos e os autores mais citados.

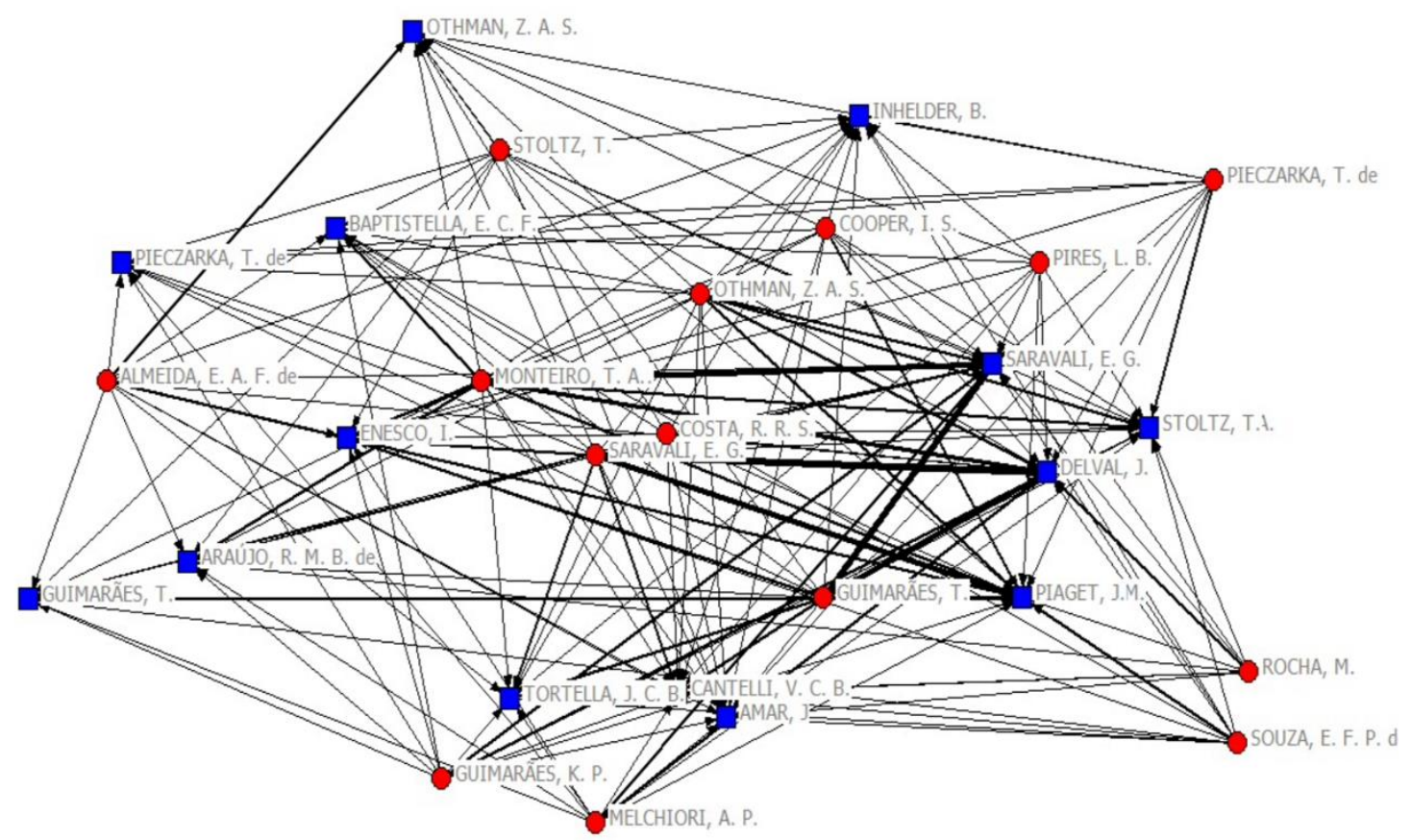

Fonte: Elaborado pelas autoras.

É possível observar que há uma forte relação entre as auto-citações: a título de exemplificação, Saravali, E. G. se cita 36 vezes. Delval, J. é um dos autores mais citadossendo, por exemplo, citado122 vezes nas publicações de Saravali, E. G. e 93 vezes por Guimarães, T.; juntamente com Piaget, J., citado 82 e 75 vezes, respectivamente, pelas mesmas autoras. Esses dois maiores valores representam $50 \%$ do total de citações.

Os dados apresentados indicam que Juan Delval é a grande referência dos trabalhos brasileiros, influenciando a maioria absoluta das pesquisas, superado somente por Piaget que compõe a fundamentação teórica das investigações. Esta influência se dá, sobretudo, pela delimitação do campo, realizada pelo espanhol, que permite ao interessado no assunto compreender as peculiaridades da adoção do conhecimento social numa abordagem piagetiana. Soma-se a isso o fato de que algumas das pesquisas brasileiras são réplicas dos trabalhos desenvolvidos no exterior, apoiando-se, sobretudo, 
nos instrumentos (entrevistas clínicas) já utilizados no contexto internacional.

As similaridades encontradas na evolução das respostas, nestes diferentes estudos e em seus contextos, nos confirmam aspectos teóricos importantes, enunciados na obra piagetiana, bem como nos alerta a respeito da relevância da continuidade das investigações na área.

A questão da auto-citação pode estar relacionada a ausência de levantamento bibliográfico de estudos na área o que gera uma visão menos abrangente do que já se estudou/publicou; algo dificultado, também, pela pouca publicação das pesquisas em bases de dados mais acessadas, ou, ainda, em veículos indexados nessas bases, tais como artigos científicos. Isso gera certa endogenia por parte dos autores que acabam referenciando somente seus próprios trabalhos e/ou os trabalhos do grupo de pesquisa do qual fazem parte.

Outro aspecto a se considerar, a respeito da auto-citação, indicaque as pesquisas sobre a construção do conhecimento social são relativamente recentes, com muitas temáticas pouco desenvolvidas o que acaba por limitar as opções de referenciamento para um autor. De qualquer forma, é sempre importante considerar que ao citar seu próprio trabalho o autor confirma uma tese que vem explorando em outros estudos.

O Gráfico 1 ilustra a dispersão, ou seja, a associação e a correlação entre os autores mais produtivos e os mais citados, das citações ocorridas dentre todos os autores analisados. 
Gráfico 1: Citações entre os autores mais produtivos.

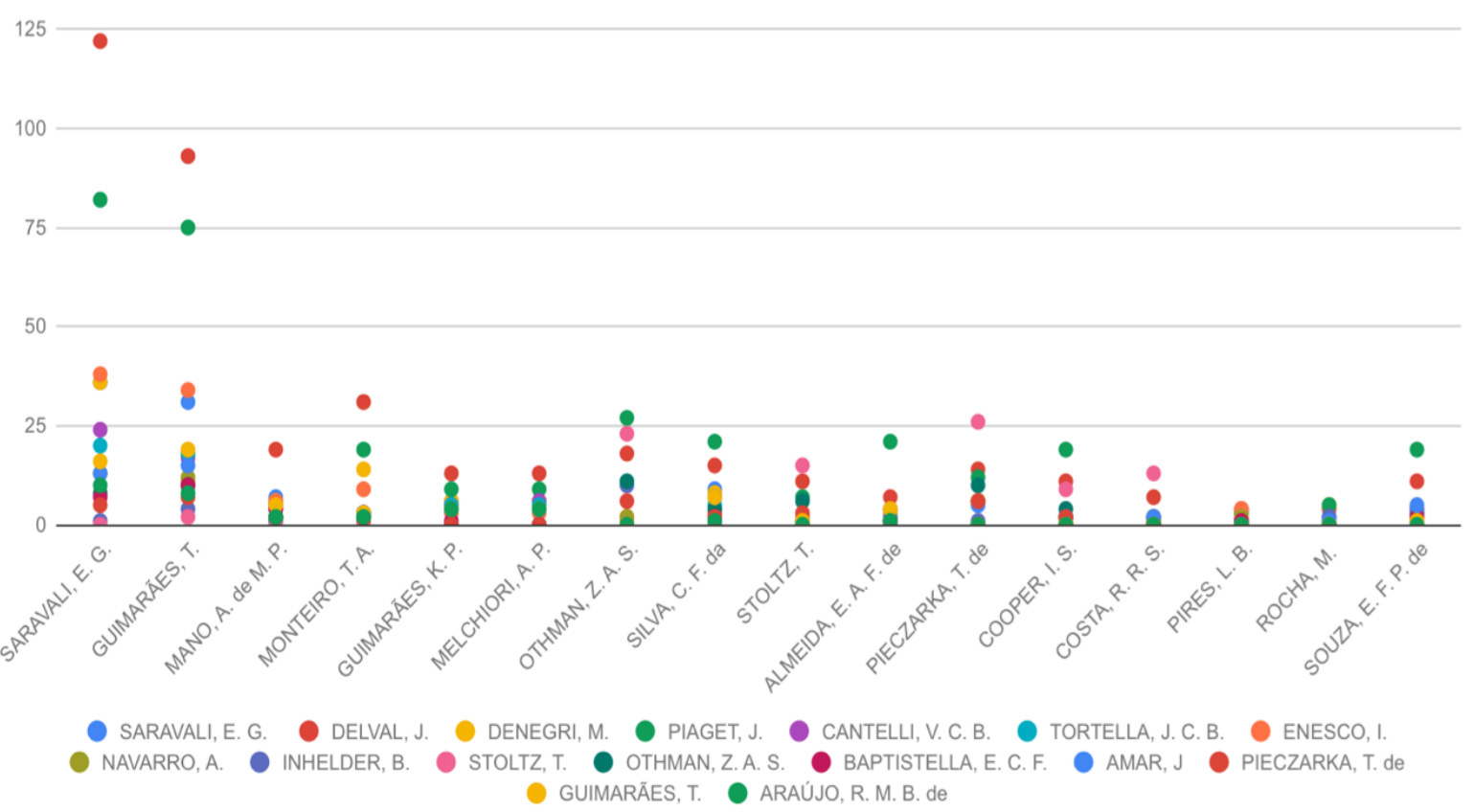

Fonte: Elaborado pelas autoras.

A linha horizontal do gráfico mostra os 16 autores mais produtivos na área e a linha vertical mostra o quanto foram citados em suas próprias produções ou nas produções de outros autores. Isso nos permite visualizar a Lei do Elitismo de Price, ou seja, o quanto os autores mais produtivos estão sendo citados e, assim, perceber qual o impacto dos mesmos para a elaboração de novas produções acadêmicas na área do estudo em questão.

A título de exemplificação, Saravali, E. G. cita ela mesma, Delval, J., Denegri, M., Piaget, J., Cantelli, V. C. V., Tortella, J. C. B., Enesco, I., Navarro, A., Inhelder, B., Othman, Z. A. S., Baptistella, E. C. F., Amar, J., Pieczarka, T. de, Guimarães T. e Araújo, R. M. B. de. Na mesma linha de pensamento, Rocha, M.cita Delval, J., Denegri, M., Piaget, J., Cantelli, V. C. B., Inhelder, B. e Amar, J.

Nessa perspectiva, podemos perceber que Delval, J. e Piaget, J. se destacam dentre os autores mais citados, enquanto que Saravali, E. G. e Guimarães, T. são salientadas como autoras mais produtivas dentre os autores mais produtivos. 
Analisamos, também, a origem desses trabalhos, considerando a Universidade em que a publicação aparece, quando se trata de teses, dissertações e TCCs; bem como o professor orientador mencionado. No caso de artigos, anais e capítulos foi considerada a autoria do trabalho e a vinculação à Universidade ou a um grupo de pesquisa, no momento da publicação. Para essa análise, optou-se por referenciar os orientadores e os grupos de pesquisa, na intenção de facilitar ao leitor o acesso aos locais em que a temática do conhecimento social é um objeto de pesquisa mais consolidado.

Deste modo, temos 47 trabalhos vinculados à UNESP -Universidade Estadual Paulista “Júlio de Mesquita Filho", campus de Marília-SP onde se concentram os estudos com delineamentos interventivos; 9 vinculados à UFPR - Universidade Federal do Paraná, com trabalhos mais específicos sobre o mundo econômico; 6 pertencentes ao Laboratório de Psicologia Genética da UNICAMP, com temáticas variadas; 6 produzidos na Universidade Federal de Viçosa - MG, nos quais predominam as temáticas relacionadas à escola e 2 no Centro Universitário Moura Lacerda. Outras 4 produções foram vinculadas às seguintes instituições, com um produto cada: UNESP -Universidade Estadual Paulista "Júlio de Mesquita Filho", campus de Araraquara-SP; USP - Universidade de São Paulo; UFPE - Universidade Federal da Pernambuco e Instituto Taquaritinguense de Ensino Superior.

O gráfico 2, a seguir, ilustra esses dados.

Gráfico 2: Instituições de origem das pesquisas

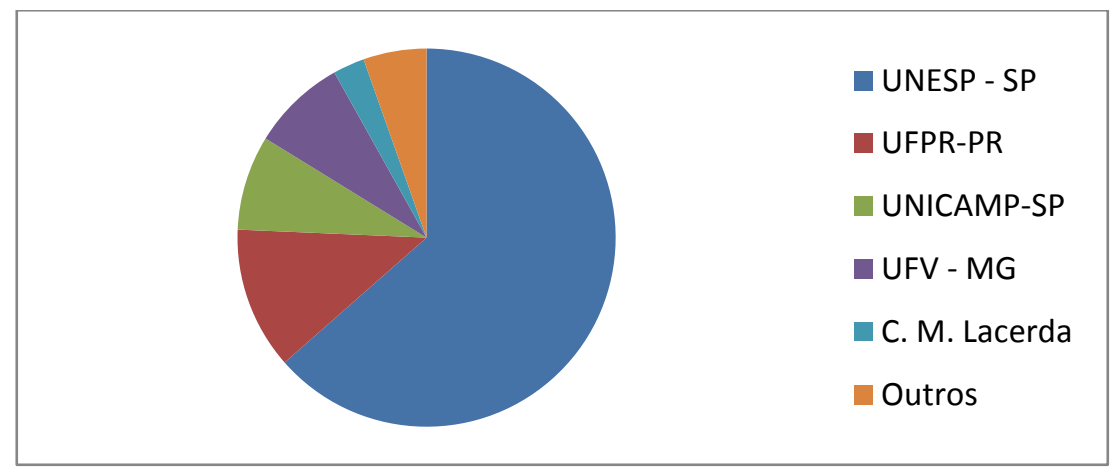

Fonte: Elaborado pelas autoras. 
$\mathrm{Na}$ Tabela 4, a seguir, encontra-se a referência aos orientadores e grupos de pesquisa, cadastrados no diretório de grupos do $\mathrm{CNPq}$, aos quais esses trabalhos estão vinculados.

Tabela 4: Grupos de pesquisas e orientadores.

\begin{tabular}{|c|c|c|}
\hline INSTITUIÇÕES & $\begin{array}{c}\text { PESQUISADOR } \\
\text { (ORIENTOU OU } \\
\text { CONDUZIU A } \\
\text { PESQUISA) }\end{array}$ & $\begin{array}{c}\text { GRUPO DE PESQUISA } \\
\text { CNPQ }\end{array}$ \\
\hline UNESP & Eliane Giachetto Saravali & $\begin{array}{l}\text { GEADEC - Grupo de } \\
\text { Estudos e Pesquisas em } \\
\text { Aprendizagem e } \\
\text { Desenvolvimento na } \\
\text { Perspectiva Construtivista }\end{array}$ \\
\hline UFPR & Tania Stoltz & $\begin{array}{l}\text { Cognição, Aprendizagem e } \\
\text { Desenvolvimento Humano }\end{array}$ \\
\hline UNICAMP & $\begin{array}{l}\text { Orly Zucatto Mantovani } \\
\text { de Assis }\end{array}$ & $\begin{array}{l}\text { LPG - Laboratório de } \\
\text { Psicologia Genética }\end{array}$ \\
\hline UFV & $\begin{array}{l}\text { Maria de Lourdes Mattos } \\
\text { Barreto }\end{array}$ & $\begin{array}{l}\text { Contextos da infância, } \\
\text { adolescência e juventude e } \\
\text { suas inter-relações na } \\
\text { família e na sociedade }\end{array}$ \\
\hline C.M.LACERDA & $\begin{array}{l}\text { Carmen Campoy } \\
\text { Scriptori }\end{array}$ & $\begin{array}{l}\text { Pesquisadora vinculada ao } \\
\text { LPG e ao GEADEC }\end{array}$ \\
\hline
\end{tabular}

Fonte: Elaborada pelas autoras.

Em todos esses estudos, observam-se, ainda, algumas questões importantes. A idade dos participantes destas investigações se concentra na faixa etária entre 6 e 14 anos o que, segundo o referencial teórico piagetiano, abarcaria os estádios pré-operatório, operatório concreto e operatório formal. Somente o estudo de Cooper (2011) foi realizado com sujeitos mais velhos, 20 e 40 anos. 
Essa concentração está diretamente relacionada ao delineamento de pesquisa mais adotado - o estudo evolutivo transversal - em que se investiga uma noção ao longo do desenvolvimento, por meio de recortes etários. Esse tipo de delineamento, presente em mais da metade das produções é, também, muito encontrado nos trabalhos internacionais.

Todavia, algo curioso nos dados brasileiros é uma diferença na evolução dos níveis de construção do conhecimento social, indicados por Delval (2002). Enquanto as pesquisas internacionais apontam para o alcance de noções mais elaboradas, classificadas como de nível III, por volta dos 14 anos, no Brasil, há um relativo atraso e mesmo em pesquisas com participantes de 16 anos não se observa a presença do nível III. Isso significa que, mesmo em idades mais avançadas, há ainda a predominância de ideias mais simplistas e rudimentares em diferentes conteúdos do mundo social (COSTA, 2009; PIECZARKA, 2009; COOPER, 2011; SARAVALI et al, 2013).

Alguns trabalhos mais recentes abordam esse atraso, objetivando explicá-lo mediante a análise do desenvolvimento cognitivo e a construção do raciocínio operatório e formal. Nestes estudos, (MANO; SARAVALI, 2014; SOUZA; SARAVALI, 2016), são apresentadas relações entre as construções sociais e as lógico-matemáticas, de tal forma que noções sociais mais elaboradas necessitam estar acompanhadas de um desenvolvimento cognitivo formal; portanto, considerando a faixa etária predominante, percebe-se um atraso no desenvolvimento que possui consequências nefastas para além dos problemas relacionados à construção do conhecimento social. De qualquer forma, para o conhecimento social, em específico, elevar a faixa etária para a realização de novas investigações é um procedimento importante e que pode nos explicar melhor a maneira como esse atraso permanece ou se dissipa.

Os delineamentos evolutivos transversais, como dissemos, são os predominantes e tem a vantagem de nos mostrar como uma noção pode se apresentar em momentos diferentes do desenvolvimento. Alguns destes estudos investigam a influência do nível sócio-econômico na construção da 
noção social em questão (PIRES; ASSIS, 2005), outros analisam a construção do conhecimento social para papéis sociais diferentes (OTHMAN, 2006), ou, ainda, em ambientes sociais diferenciados (MONTEIRO, 2013). Para o campo pedagógico, conhecer essa evolução, bem como os fatores que a influenciam ou não, pode ajudar os mestres na seleção de atividades mais condizentes com as possibilidades reais de seus alunos, respeitando-se os processos cognitivos que os mesmos percorrem.

Nesta mesma linha de trabalhos de cunho diagnóstico, temos os estudos de caso, (26\% das pesquisas encontradas), que promovem uma análise a partir de um número menor de participantes com concentração numa determinada faixa etária. Entre eles, destacamos a pesquisa de Saravali e Guimarães (2010).

Nesse sentido, é interessante notar o número pequeno de delineamentos interventivos, sobretudo aqueles voltados a auxiliar/problematizar a evolução das noções encontradas. Nos trabalhos encontrados nessa linha (SARAVALI, 2005; ARAÚJO, 2007; GUIMARÃES, 2012; ALMEIDA; SARAVALI, 2015; GUIMARÃES, 2017), percebemos como é possível promover a construção desse tipo de conhecimento, mediante a organização de intervenções pedagógicas voltadas aos processos de equilibração e que promovem um avanço na construção de diferentes noções. A realização de mais investigações com esse caráter nos parece uma necessidade importante da área de Educação.

Ainda no que se refere aos aspectos metodológicos dessas pesquisas, destacamos que o instrumento mais utilizado, em maioria absoluta, é a entrevista clínica, também denominada por entrevista semi-estruturada, motivadas (SILVA, 2009; ROCHA, 2009; ALMEIDA, 2015) ou não (GRANJA, 2012) por apresentação de figuras/fotos e pautadas no método clínico-crítico piagetiano (PIAGET, 1967; 1979). Os pesquisadores procuram, assim, aproximar-se das interpretações dos participantes por meio de uma entrevista especialmente desenvolvida para a avaliação de crenças 
desencadeadas e/ou espontâneas, interessantes aos olhos do pesquisador piagetiano.

A entrevista clínica é seguida, em menor escala, pela apresentação e análise de histórias com (RAVAGNANI, 2006) ou sem material de apoio (SOARES, 2012); realização e interpretação de desenhos (SARAVALI, 2005; GARCIA; SARAVALI, 2014); apresentação e interpretação de filmes (MONTEIRO, 2013). Com esse tipo de instrumentação, os pesquisadores evitam a abordagem direta sobre temas mais complexos, sobretudo junto a sujeitos menores.

Delval (2007) nos explica que o conhecimento social possui diferentes campos, doravante denominado por nós de temas. Cada tema explora diferentes questões sociais, com características específicas, mais ou menos complexas.

Os distintos campos da representação do mundo social possuem características diferentes e graus de dificuldade desiguais. Em alguns casos, trata-se simplesmente de compreender regulamentos simples sobre certos usos sociais. Em outros, é necessário entender sistemas simples, muitos dos quais podem ser compreendidos de uma forma concreta. Isso acontece, por exemplo, com muitas vertentes da ideia de país. Por outro lado, há casos em que se trata de entender um sistema muito amplo que, por sua vez, possui subsistemas que interagem com ele, como é o caso da organização econômica ou da organização política da sociedade, que se mostra muito complexa de se entender, e sua compreensão parece exigir instrumentos do tipo formal. (DELVAL, 2007, p. 59, tradução nossa).

Em relação aos temas pesquisados nas investigações brasileiras, temos um predomínio dos trabalhos voltados à construção do pensamento econômico. Entre eles, destacamos: a noção de lucro (PIRES; ASSIS, 2005; COSTA, 2009); a noção de mobilidade social (PIECZARKA, 2009; ARAÚJO; GOMES, 2010); e o consumo (ROCHA et al., 2012). Essa temática esteve presente em $30 \%$ das produções analisadas. 
Em seguida, temos 20\%dos estudos voltados a aspectos que envolvem as instituições escolares, como o papel do professor (GUIMARÃES; SARAVALI, 2010), as situações de aprendizagem e não aprendizagem (SARAVALI et al., 2013; GARCIA; SARAVALI, 2014) e a própria noção de escola (SARAVALI; GUIMARÃES, 2010; COSTA, 2012).

Encontramos 4trabalhos, (11\%), a respeito de questões ambientais (FERREIRA, 2008; MELLO, 2008, GUIMARÃES, 2012 e 2017) e 2,6\%, sobre violência (MONTEIRO; SARAVALI, 2011; MONTEIRO, 2013). Outros temas também apareceram de forma isolada em nosso levantamento, ou seja, com uma referência no período, em destaque: trabalho (SILVA, 2009), festas escolares (OLIVEIRA, 2010), etnia (ALMEIDA, 2015), origem da Terra e da vida (MANO; SARAVALI, 2012), direitos das crianças (SILVA, 2017).

A revisão mais cuidadosa do estado do conhecimento, antes do início de uma investigação, pode auxiliar o pesquisador a optar por temas ainda pouco explorados no Brasil. Há, ainda, a possibilidade de se investigar temas originais, específicos da nossa realidade, mediante a criação de instrumentos metodológicos novos, sem apoio nos estudos internacionais. Observamos que a repetição de algumas temáticas em estudos diferentes nem sempre nos trazem dados inéditos ou desconhecidos.

\section{Considerações}

Nosso objetivo, no presente artigo, consistiu em oferecer àqueles que estudam e/ou pesquisam a respeito do conhecimento social, numa perspectiva piagetiana, um panorama detalhado do que se investigou em nosso país entre os anos de 2005 e 2017. Pretendemos, também, oferecer ao leitor, uma análise e a sistematização desses estudos, de modo a facilitar o acesso às produções, e a seus conteúdos, e auxiliar o pesquisador em análises mais aprofundadas no que tange a alguns aspectos, a saber: veículo de publicação, autores mais produtivos, autores mais citados, instituições de 
origem das pesquisas, faixa etária dos participantes, delineamentos metodológicos utilizados e as temáticas abordadas.

Após essa extensa análise, ressaltamos alguns aspectos:

1) Os pesquisadores da área citam pouco os estudos brasileiros quando estes se encontram fora de seus próprios grupos de pesquisa. Tal fato, além de favorecer uma valorização dos trabalhos internacionais, em detrimento dos nacionais, permite a realização de pesquisas semelhantes que acabam não inovando em seus dados;

2) Há grupos constituídos no país que devem ser considerados como referências para os novos estudos da área;

3) Para a Educação, os delineamentos interventivos, ainda bastante escassos, podem ser bastante interessantes a pesquisadores, estudiosos e professores, com reais possibilidades de contribuição para a melhoria da educação básica;

4) Há necessidade em se aumentar a faixa etária dos estudos realizados com nossos participantes a fim de se verificar a construção e evolução das noções sociais em nosso contexto;

5) Há temáticas mais exploradas e outras ainda inéditas a serem pesquisadas no Brasil.

Acreditamos que todos esses trabalhos e os dados apresentados apontam para a atualidade dos estudos sobre a temática. Nesse sentido, é importante ressaltar que nosso levantamento ocorreu até o mês de agosto de 2017 e que, dada a atualidade, novos trabalhos podem ter sido realizados após esse período, ou lançados nas bases de dados que investigamos após o mês de agosto. Portanto, sugerimos que o pesquisador interessado nessa atualização rigorosa proceda a novo levantamento do ano de 2017. Sobre isso, cumpre destacar que, no momento da finalização do presente artigo, tivemos conhecimento de três novas produções: Peralta; Oliveira (2017); Freire (2017); Peralta (2017). 
Longe de esgotarmos o assunto, a sequência destes trabalhos e o aprofundamento de estudos na área contribuirão para a compreensão a respeito da construção do conhecimento social, nas áreas pedagógica, psicológica e epistemológica.

Destaque-se, ainda, a atualidade e a importância da obra piagetiana, que oferece o suporte teórico para as interpretações específicas sobre a apropriação do mundo social, evidenciadas nos estudos apresentados aqui.

\section{Referências}

ALMEIDA, E. A. Intervenção pedagógica e construção de noções étnicas por meio da pesquisa escolar: um estudo piagetiano. 2015. 280f.Dissertação (Mestrado em Educação) -Universidade Estadual Paulista, Marília, 2015.

ALMEIDA, E. A. F.; SARAVALI, E. G.Construção de concepções étnicos-raciais africanas em sala de aula. In: REUNIÃO NACIONAL DA ANPED, 37., 2015, Florianópolis. Anais... Florianópolis: ANPED, 2015.

ALVARADO, R. U. Elitismo na literatura sobre a produtividade dos autores. Ciência da Informação, Brasília, v. 38, n. 2, p. 69-79, maio/ago. 2009. Disponível em: < http://revista.ibict.br/ciinf/article/view/1246/1424>. Acesso em: 14 dez. 2017.

ARAÚJO, R. M. B. O desenvolvimento do pensamento econômico em crianças: avaliação e intervenção em classes de $3^{\mathrm{a}}$ e $4^{\mathrm{a}}$ série do Ensino Fundamental. 2007. Tese (Doutorado em Educação) - Faculdade de Educação, Universidade de Campinas, Campinas, 2007.

ARAÚJO, A. S.; GOMES, L. R. A noção de mobilidade social em adolescentes. Educar em Revista, Curitiba, v.26, n.38, set./dez., 2010, p. 193- 204. Disponível em: $<\mathrm{http}: / /$ revistas.ufpr.br/educar/article/view/12360>. Acesso em: 10 jul. 2017.

COOPER, I. S. Cartão de crédito: salvação ou perdição? Representações de adultos jovens sobre instituições financeiras e utilização de cartão de crédito. 2012. 268f. Dissertação (Mestrado em Educação) - Setor de Educação, Universidade Federal do Paraná, Curitiba, 2011.

COSTA, B. de A.Com a voz as crianças: um estudo sobre as representações de escola na educação infantil. 2012. Dissertação (Mestrado em Economia Doméstica) - Faculdade de Economia, Universidade Federal de Viçosa, Viçosa, 2012.

COSTA, R. R. S. O mundo econômico em questão: como crianças e adolescentes escolarizados entendem o lucro? 2009. 303 f. Dissertação (Mestrado em Educação) Universidade Federal do Paraná, Curitiba, 2009. 
DELVAL, J. Aspectos de la construcción del conocimiento sobre la sociedad. Educar em revista. Curitiba: Editora da UFPR, n. 30, p.45-64, 2007.

. El aprendizaje y la enseñanza de las ciencias experimentales y sociales. México: Siglo XXI Editores, 2013a.

. Descubrir el pensamiento de los niños. México: Siglo XXI Editores, 2013b.

.Introdução à prática do método clínico: descobrindo o pensamento das crianças. Tradução Fátima Murad. Porto Alegre: Artmed, 2002.

.La representación infantil del mundo social. In: TURIEL, E., ENESCO, I. y LINAZA, J. (comps.). El mundo social en la mente del niño. Madrid: Alianza, 1989.

.DEL BARRIO, C. Las ideas de los niños acerca de la guerra y la paz.MARTÍN, F.; BURILLO, F. (coord.).La guerra: realidad y alternativas. Madrid: Editorial Complutense, 1992. p.165-175.

. .; VILA, I. Los niños y Dios: ideas infantiles sobre la divinidad, los orígenes y la muerte. México: Siglo Venitiuno Editores, 2008.

; DELVAL, J. Concepciones evolutivas acerca de la fabricación del dinero. Los niveles de comprensión. Investigación en la Escuela, v. 1, n. 48, p.39-54. 2002a.

.; C__ Concepciones evolutivas acerca de la fabricación del dinero. Los tipos de respuestas. Investigación en la Escuela, v. 1, n. 48, p.55-70. 2002b.

ENESCO; I., DELVAL, J.; LINAZA, J. Conocimiento social y no social. In: TURIEL, E., ENESCO, I.; LINAZA, J. El mundo social em la mente infantil. Madrid: Alianza Editorial, 1989.

FERREIRA, L. M. Concepção de crianças de 4 a 6 anos sobre o consumo de água: uma abordagem baseada no método clínico. 2008. 136 f. Dissertação (Mestrado em Economia doméstica) - Faculdade de Economia, Universidade Federal de Viçosa, Viçosa, 2008.

FREIRE, J. F. de C. Direito de expressão, protesto e greve: noções sociais construídas por alunos de diferentes níveis de escolaridade e os processos de generalização. 2017. 124 f. Dissertação (Mestrado em Educação) - Universidade Estadual de Londrina, Londrina, 2017.

GARCIA, M. A.; SARAVALI, E. G. Aprender e não aprender por quem não aprende: um estudo evolutivo psicogenético. Linha Mestra, Campinas, n. 24, jan./jul. 2014, p. 1114-1119.

Disponível

em: $<$ https://repositorio.unesp.br/bitstream/handle/11449/115372/ISSN19809026-201424-1114-1119.pdf; sequence=1>. Acesso em: 09 fev. 2017.

GRANJA, M. C. L. O mundo econômico da criança: uma investigação psicológica sobre o dinheiro. 2012. Dissertação (Mestrado em Psicologia Cognitiva) Universidade Federal de Pernambuco, Recife, 2012. 
GODOY, E. A. de. A representação étnica por crianças pré-escolares: um estudo de caso a luz da teoria piagetiana. 1996. Dissertação (Mestrado em Educação) Faculdade de Educação, Universidade de Campinas, Campinas, 1996.

GUIMARÃES, T. A sala de aula sob o olhar piagetiano: intervenção pedagógica e construção do conhecimento social. 2017. Tese (Doutorado em Educação) Faculdade de Filosofia e Ciências, Universidade Estadual Paulista, Marília, 2017.

Intervenção pedagógica e noções sobre o meio ambiente: a construção do conhecimento social à luz da epistemologia genética. 2012. Dissertação (Mestrado em Educação) - Faculdade de Filosofia e Ciências, Universidade Estadual Paulista, Marília, 2012.

.; SARAVALI, E. G. O papel da escola e do professor numa situação de não aprendizagem: o que dizem as crianças. Educar em Revista (Impresso), p. 141-158, 2011.

LAKATOS, E. M.; MARCONI, M. de A. Fundamentos de metodologia científica. 5. ed. São Paulo: Atlas, 2003.

MANO, A. M. P. Ideias de estudantes sobre a origem da Terra e da vida e suas relações com o desenvolvimento cognitivo: um estudo psicogenético. $2013.171 \mathrm{f}$. Dissertação (Mestrado em Educação) - Faculdade de Ciências e Filosofia, Universidade Estadual Paulista, Marília, 2013.

.; GUIMARÃES, T.; SARAVALI, E. G. Estado da arte (2009-2013) de teses e dissertações sobre o conhecimento social no âmbito brasileiro. In: COLÓQUIO INTERNACIONAL DE EPISTEMOLOGIA E PSICOLOGIA GENÉTICAS, 3., 2013, João Pessoa. Anais...João Pessoa: Universidade Federal da Paraíba, 2013.

.; _ _ A construção da noção de origem da vida na terra sob o enfoque psicogenético. In: ENCONTRO NACIONAL DE DIDÁTICA E PRÁTICAS DE ENSINO, 16., 2012, Campinas. Anais...Campinas: Junqueira \& Marin Editores, 2012.

; __ G. As relações entre a construção da abstração reflexionante e o conhecimento social: um estudo psicogenético. Revista de Educação Pública, Cuiabá, v. 23, p. 759-779, 2014.

MELLO, J. de A. S. Conhecendo as idéias das crianças sobre produção e destinação do lixo doméstico e escolar.2008. 126f. Dissertação (Mestrado em Educação) Faculdade de Educação, Centro Universitário Moura Lacerda, Ribeirão Preto, $2008 . \quad$ Disponível em: $<$ http://mestrado.mouralacerda.edu.br/arquivos/dissertacoes/dissertacao_51.pdf $>$. Acesso em 7 mai. 2013.

MONTEIRO, T. A. A construção da noção de violência em crianças e adolescentes inseridos em diferentes contextos. 2013. Dissertação (Mestrado em Psicologia) Instituto de Psicologia, Universidade de São Paulo, São Paulo. 2013. 
.; SARAVALI, E. G. Psicogênese da noção de violência: um estudo evolutivo a partir da perspectiva piagetiana. Educação: Revista do Centro de Educação da UFSM, v. 36, n. 12, maio/ago., 2011, p. 279-296. Disponível em: $<$ https://periodicos.ufsm.br/reveducacao/article/view/2361>. Acesso em: 18 jan. 2018.

OLIVEIRA, R. M. Sentidos e significações das festas escolares: implicações para a construção do conhecimento social e da noção de cidadania. 2010. 99 f. Dissertação (Mestrado em Educação)- Centro Universitário Moura Lacerda, Ribeirão Preto, 2010.

OTHMAN, Z. A. Compreensão da noção de lucro em crianças e adolescentes vendedores e não vendedores de rua de Curitiba. 2006. 179f. Dissertação (Mestrado em Educação) - Setor de Educação, Universidade Federal do Paraná, Curitiba, 2006.

PERALTA, T. P. A relação entre escola e trabalho: noções sociais e processos de generalização na perspectiva de crianças e adolescentes. 98 f. Dissertação (Mestrado em Educação). Universidade Estadual de Londrina, Londrina, 2017.

PERALTA, T.; OLIVEIRA, F.N. A relação entre escola e trabalho: a realidade social na perspectiva de crianças. Educação em Questão, UFRN, Natal, v. 55, n. 45, p. 200-226, jul./set. 2017.

PIAGET, J. Psicologia e pedagogia. Rio de Janeiro: Forense universitária, 1998.

. A representação do mundo na criança. Rio de Janeiro: Record, 1979.

. O raciocínio na criança. Rio de Janeiro: Record, 1967.

PIECZARKA, T. Concepções de desigualdade social e mobilidade socioeconômica de adolescentes de escola pública de Curitiba. 2009. 255f. Dissertação (Mestrado em Educação) - Universidade Federal do Paraná, Curitiba, 2009.

PIRES, L.; ASSIS, O. Z. M. As representações das crianças sobre a noção de lucro: a construção do conhecimento social numa perspectiva construtivista. In: Encontro Nacional de Professores do Proepre, 22., 2005, Campinas. Anais... Campinas: UNICAMP/FE/LPG, 2005. p. 471.

PRICE, J. D. de S. Litle science, big science. New York: Columbia University Press, 1963.

RAVAGNANI, M. C. A. N. Autoridade autoritarismo e autonomia docente: representações de professores e alunos. 2006. 257f. Tese (Doutorado em Educação) Universidade Estadual Paulista, Araraquara, 2009.

ROCHA, M. Estudo da representação sobre os recursos monetários e a sua relação com o consumo por crianças e adolescentes, em uma perspectiva piagetiana,2009. 267f. Dissertação (Mestrado em Economia Doméstica) - Universidade Federal de Viçosa. 2009. 
et al. As representações de crianças e adolescentes sobre a inter-relação entre os recursos monetários e o consumo numa perspectiva. Revista Brasileira de Economia Doméstica, Viçosa,v.23, n. 2, 2012, p. 142-162. Disponível em: $<$ http://www.seer.ufv.br/seer/oikos/index.php/httpwwwseerufvbrseeroikos/article/vi ew/118/129>. Acesso em: 10 set. 2017.

SARAVALI, E. G. Trabalhando os direitos das crianças numa sala de educação infantil. In: REUNIÃO ANUAL DA ANPED, 28., 2005, Caxambú. Anais... Caxambú: ANPED, 2005. p.1-25.

; GUIMARÃES,T. Ambientes educativos e conhecimento social: um estudo sobre as representações de escola. Educação em revista, Belo Horizonte, v.26, n.1, 2010

.; ___ GUIMARÃES, K. P.; MELCHIORI, A. P. Crenças envolvendo o não aprender: um estudo evolutivo sobre a construção do conhecimento social. Educação em Revista, Belo Horizonte, v. 29, n.3, p. 143-176, 2013. Disponível em:<http://educa.fcc.org.br/pdf/edur/v29n03/v29n03a07.pdf $>$. Acesso em: 25 jun. 2014.

.; MANO, A. de M.; GUIMARÃES, T. As relações entre a construção do conhecimento social e lógico-matemático: o que dizem as pesquisas brasileiras. In: ENCONTRO NACIONAL DE DIDÁTICA E PRÁTICA DE ENSINO, 17., 2015, Fortaleza. Anais... Fortaleza: EdUCE, 2015.

SOARES, O. M. A. A representação de crianças e adolescentes sobre a inclusão escolar. 2012. 171f. Dissertação (Mestrado em Economia Doméstica) Universidade Federal de Viçosa. 2012.

SOUZA, E.; SARAVALI, E.G. As relações entre o raciocínio lógico-matemático e a construção do conhecimento social: um estudo evolutivo. Cadernos de Educação, Pelotas, n.53, p.101-122, 2016.

SILVA, M. O. da. Representações de crianças e adolescentes sobre trabalho numa perspectiva piagetiana. 2009. 283f. Dissertação (Mestrado em Economia Doméstica) - Universidade Federal de Viçosa, Viçosa, 2009.

SILVA, C. F. da. A construção da noção de direito em alunos do $3^{\circ}$ ano do Ensino Fundamental. uma pesquisa-ação na perspectiva piagetiana. 2017.Dissertação (Mestrado em Educação) - Faculdade de Filosofia e Ciências, Universidade Estadual Paulista, Marília, 2017.

TORTELLA, J.C.B. Amizade no contexto escolar. 1996. Dissertação (Mestrado em Educação) - Faculdade de Educação, Universidade de Campinas, Campinas, 1996. 